\title{
The fate of buried organic carbon in colluvial soils: a long-term perspective
}

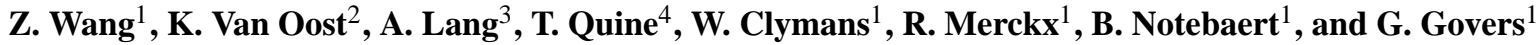 \\ ${ }^{1}$ Department of Earth and Environmental Sciences, K.U. Leuven, Heverlee, Belgium \\ ${ }^{2}$ Earth \& Life Institute (TECLIM), Université catholique de Louvain, Louvain-la-Neuve, Belgium \\ ${ }^{3}$ School of Environmental Sciences, University of Liverpool, Liverpool, UK \\ ${ }^{4}$ Department of Geography, College of Life and Environmental Sciences, University of Exeter, Exeter, UK
}

Correspondence to: Z. Wang (zhengang.wang@uclouvain.be)

Received: 8 May 2013 - Published in Biogeosciences Discuss.: 19 August 2013

Revised: 25 December 2013 - Accepted: 7 January 2014 - Published: 13 February 2014

\begin{abstract}
Colluvial soils are enriched in soil organic carbon (SOC) in comparison to the soils of upslope areas due to the deposition and progressive burial of SOC. This burial of SOC has important implications for the global carbon cycle, but the long-term dynamics of buried SOC remain poorly constrained. We addressed this issue by determining the SOC burial efficiency (i.e. the fraction of originally deposited SOC that is preserved in colluvial deposits) of buried SOC as well as the SOC stability in colluvial soils. We quantified the turnover rate of deposited SOC by establishing sediment and SOC burial chronologies. The SOC stability was derived from soil incubation experiments and the $\delta^{13} \mathrm{C}$ values of SOC. The $\mathrm{C}$ burial efficiency was found to decrease with time, reaching a constant ratio of approximately $17 \%$ by about $1000-1500 \mathrm{yr}$ post-burial. This decrease is attributed to the increasing recalcitrance of the remaining buried SOC with time and a less favourable environment for SOC decomposition with increasing depth. Buried SOC in colluvial profiles was found to be more stable and degraded in comparison to SOC sampled at the same depth at a stable reference location. This is due to the preferential mineralisation of the labile fraction of the deposited SOC. Our study shows that SOC responds to burial over a centennial timescale; however, more insight into the factors controlling this response is required to fully understand how this timescale may vary, depending on specific conditions such as climate and depositional environment.
\end{abstract}

\section{Introduction}

There are significant uncertainties associated with our understanding of the role of soil erosion in the global C cycle (e.g. Van Oost et al., 2007; Berhe et al., 2007; Lal, 2003). To a large extent, these uncertainties originate from the difficulties associated with quantifying the fate of the eroded soil organic carbon (SOC). The SOC mobilised by water erosion can be released into the atmosphere, re-deposited within the catchment or exported from the catchment. Various studies have been conducted to explore the fate of the SOC exported from the catchment: for instance, labile young organic matter delivered to river systems was found to be rapidly mineralised in the channel (e.g. Raymond and Bauer, 2001; Mayorga et al., 2005), while SOC reaching lakes and oceans has been shown to be well preserved over longer timescales (e.g. Rosen and Hammarlund, 2007; Galy et al., 2007).

Rather than reaching the fluvial system, where previously eroded SOC can be stored effectively in freshwater sediments, a substantial fraction of the sediment mobilised by soil erosion is re-deposited within the landscape in colluvial stores. The hillslope sediment delivery ratio, i.e. the ratio between the amount of sediment mobilised by erosion and exported to the fluvial system, for agricultural catchments in temperate climates is estimated to be between 20 and $50 \%$ (Rommens et al., 2005; Notebaert et al., 2011; Trimble, 1999; Wang et al., 2010). Thus, 50-80\% of the eroded sediments are re-deposited on hillslopes and form colluvial soils (Wang et al., 2010). 
Studies covering a wide range of environments have shown that depositional sites on hillslopes accumulate and protect SOC derived by soil erosion (e.g. Ritchie et al., 2007; Li et al., 2007; Zhang et al., 2006; VandenBygaart et al., 2012; Van Oost et al., 2005a; Smith et al., 2005; Quine and Van Oost, 2007). Carbon burial in colluvial soils removes C from the actively cycling $\mathrm{C}$ pools in the surface layers to the subsoil, where it continues to decompose, albeit at a slower rate. Although colluvial soils may therefore store more $\mathrm{C}$ than non-eroding soils, the rate at which the buried SOC cycles remains poorly quantified: on the one hand, ${ }^{137} \mathrm{Cs}$ and $\mathrm{C}$ inventory measurements showed that a substantial part of the deposited $\mathrm{C}$ in the colluvial soils of first-order catchments is effectively protected on the timescale of $50 \mathrm{yr}$ (Van Oost et al., 2007); on the other hand, studies covering millennial timescales showed that colluvial sediments on the Belgian loess belt that were deposited several centuries to millennia ago are typically depleted in SOC relative to the source areas (e.g. Vancampenhout et al., 2008; Van Oost et al., 2012), indicating that the deposited $\mathrm{C}$ in colluvial soils is at least partially mineralised on the timescale of several centuries.

Further evidence is provided by studies that have addressed changes in the quality of buried SOC over time. Thomsen et al. (2008) investigated the characteristics of SOC buried for $3300 \mathrm{yr}$ in a Bronze Age burial mound through nuclear magnetic resonance and soil incubation experiments. They observed that the buried soils had less $\mathrm{C}$ than soils at the surface, and that the quality of the buried SOC also changes with time; relative to the young surface soils, the older and buried soils were depleted in labile components and enriched in recalcitrant compositions. Berhe et al. (2008) investigated the replacement of eroded $\mathrm{C}$ and decomposition rates at depositional locations under natural grassland vegetation using measurements of net primary production, radiocarbon and soil incubation experiments. They found that the SOC decomposition rate was 2 to 14 times slower in the depositional settings when compared to the eroding slopes, and concluded that burial of $\mathrm{C}$ provided an effective $\mathrm{C}$ sequestration mechanism. However, the fate of the buried SOC in agricultural environments, where most of the human-induced erosion and burial currently occurs (Doetterl et al., 2012b), remains poorly quantified.

In response to this shortfall, the main objective of this study is to quantify the timescales of SOC stabilisation under aerobic depositional settings on arable agricultural land in environments where sediment deposition can precisely be dated. The study was carried out along chronostratigraphies of buried sediments in fine-textured colluvial soils of the Belgian loess region. Using a combination of incubation experiments, isotopic measurements and a comparative analysis of depositional versus stable profiles, we determined the stability and quality of the deposited C. Here we also discuss C dynamics in relation to sediment burial, relevant controlling factors and the overall significance of colluvial $\mathrm{C}$ burial.
Table 1. Information on the study sites.

\begin{tabular}{lllll}
\hline Site & Location & $\begin{array}{l}\text { Slope } \\
(\%)\end{array}$ & $\begin{array}{l}\text { Area } \\
(\text { ha })\end{array}$ & $\begin{array}{l}\text { Land } \\
\text { use }\end{array}$ \\
\hline A & $50^{\circ} 48^{\prime} \mathrm{N}, 4^{\circ} 35^{\prime} \mathrm{E}$ & $<15$ & 1.5 & Cropland \\
$\mathrm{B}$ & $50^{\circ} 48^{\prime} \mathrm{N}, 4^{\circ} 35^{\prime} \mathrm{E}$ & $<20$ & 117 & Cropland \\
$\mathrm{C}$ & $50^{\circ} 46^{\prime} \mathrm{N}, 4^{\circ} 44^{\prime} \mathrm{E}$ & $<28$ & 103 & Cropland \\
\hline
\end{tabular}

\section{Materials and methods}

\subsection{Study area}

The study area is located in central Belgium and has a temperate climate with a mean annual temperature of ca. $9.5^{\circ} \mathrm{C}$ and an average annual precipitation of $750-800 \mathrm{~mm}$ (Verstraeten et al., 2006). The soils in this region are mainly loess-derived Luvisols with a high silt content $(>70 \%)$ and relatively low clay $(<15 \%)$ and sand $(<20 \%)$ contents (Beuselinck et al., 2000). The study area has a rolling topography (with slopes up to $25 \%$ ), which causes a significant erosion problem (Govers, 1991; Govers et al., 1994). Today, the main crops are wheat, maize, sugar beets, potatoes and chicory. The study area has a long history of agricultural land use: deciduous forests covered the catchment during the first half of the Holocene and the first agricultural crops appeared $4000-5000$ yr ago. From the Roman period onwards, the human influence on the landscape became significant. Approximately $50 \%$ of the study area has been used for cropland agriculture since the Middle Ages and agricultural use of the land remains widespread today (Vanwalleghem et al., 2004, 2005).

\subsection{Field and laboratory work}

We selected three sites (Table 1) along a geomorphological gradient. Site A is an actively forming soil bank near a field boundary, which receives sediment from a small catchment (1.5 ha). Soil accretion at this site is mainly controlled by tillage erosion. Recent deposition rates are high and deposits are relatively young. Site B is a colluvial profile located at the outlet of a dry valley draining $117 \mathrm{ha}$. Due to a low slope gradient, this site receives sediment that is mobilised by water erosion on the steeper slopes of the upstream area of the catchment. Site $\mathrm{C}$ has a similar setting to site B (that is, it is located at the outlet of a dry valley of $103 \mathrm{ha}$ ); the sediment chronology for this site is provided by Rommens et al. (2007). At these sites, colluvial settings were characterised by taking soil cores $(2 \mathrm{~m}$ at site $\mathrm{A}$ and $4 \mathrm{~m}$ at sites $\mathrm{B}$ and C) through the full depth of colluvial deposits (these depositional sites are referred to as colluvium locations), using a percussion coring device (Wacker BH23). Furthermore, stable conditions were characterised by collecting soil cores $(1 \mathrm{~m})$ from relatively flat areas close to the drainage divide above each colluvial site (these stable sites are referred to as 
reference locations). These reference profiles can be assumed to represent stable conditions where little erosion and/or deposition has taken place. Duplicate cores were collected at all locations for the measurements of SOC, total phosphorus (P), ${ }^{137} \mathrm{Cs}$ activity and optically stimulated luminescence (OSL) dating. At site A, additional $2 \mathrm{~m}$ soil cores were taken (i.e. one from the reference location and two from the colluvium locations) for soil incubation experiments. Some compaction occurred during core collection and in data analysis, this was corrected for by linear extension of the length of the obtained soil column to the depth of the soil hole.

\subsubsection{Measurements of $\mathrm{C}$ content and $\mathrm{C}$ quality}

After sampling, the soil cores were stored below $0{ }^{\circ} \mathrm{C}$ for later laboratory processing. In the laboratory, the soil cores used for all analysis except incubation experiments were sampled at an interval of $0.05 \mathrm{~m}$, and these samples were ground and passed through a $2 \mathrm{~mm}$ sieve after oven-drying below $60^{\circ} \mathrm{C}$ for further analysis of organic $\mathrm{C}$ and total P. For samples collected from site $\mathrm{A}$, the organic carbon content and the stable $\mathrm{C}$ isotopes were measured with an ANCA 2020 GSL mass spectrometer (Sercon Ltd, UK) after removal of inorganic carbon using the HCl-fumigation method proposed by Harris et al. (2001). Isotopic ratios were expressed as $\delta^{13} \mathrm{C}(\%)$ calibrated relative to PDB. The $\delta^{13} \mathrm{C}$ value can be taken as a proxy of the degree of SOC decomposition as $\delta^{13} \mathrm{C}$ value increases with decomposition due to the kinetic fractionation (the Rayleigh effect); that is, ${ }^{12} \mathrm{C}$ is preferentially mineralised due to its lower atomic weight. Therefore, a high $\delta^{13} \mathrm{C}$ value indicates a high degree of SOC decomposition and also a high degree of SOC recalcitrance for SOC of the same origin (Natelhoffer and Fry, 1988). For samples of site $\mathrm{B}$ and $\mathrm{C}$, organic $\mathrm{C}$ and $\mathrm{N}$ were determined with a vario MAX CN macro elemental analyser (Elementar Analysensysteme $\mathrm{GmbH}$, Germany). Comparison revealed that there was no difference between the $\mathrm{C}$ content measured by these two instruments (Wang et al., 2013).

The soil cores for the incubation experiments were cut at an interval of $20 \mathrm{~cm}$ and soil was passed through an $8 \mathrm{~mm}$ sieve before air drying. For the soil incubation experiment, two replicate samples $(40-110 \mathrm{~g})$ were placed in incubation jars $(1 \mathrm{~L})$ which were tested in order to be air-tight and sprayed with de-ionised water to reach a water content of $27 \%$ (by mass), i.e. field capacity. The jars were sealed with polystyrene stoppers and kept in a room with a constant temperature of $20^{\circ} \mathrm{C}$. A 35-day pre-incubation was applied in order to avoid $\mathrm{CO}_{2}$ pulses caused by soil sample preparation (i.e. sieving, drying and rewetting; Butterly et al., 2010). The gases in the jars were collected to measure $\mathrm{CO}_{2}$ concentration. When collecting the gas samples, the headspace gases were mixed by pulling and pushing a $20 \mathrm{~mL}$ syringe 4-5 times to ensure that they were well mixed before sampling. The gases were then injected into a $12 \mathrm{~mL}$ pre-vacuumised vial for measurement of $\mathrm{CO}_{2}$ concentration.
After gas sampling, jars were opened and flushed with ambient air. Water loss during gas collection was compensated for by adding de-ionised water to the samples until reaching a water content of $27 \%$. Three empty jars were taken as controls and received the same treatments as the jars with soil samples. The $\mathrm{CO}_{2}$ concentration was measured with an isotope ratio mass spectrometer (IRMS) with a cryofocusing module (ANCA 2020, Sercon Ltd, UK). Differences in $\mathrm{CO}_{2}$ concentrations between samples and references were used to calculate the $\mathrm{CO}_{2}$ produced during the period of soil incubation. Due to the fact that the soil incubation experiments were conducted under optimal laboratory-controlled conditions, the measured soil incubation rates should be considered as potential rates of mineralisation. They should therefore be regarded as an indicator of SOC stability, i.e. an indicator of how fast (or easily) the SOC can be decomposed.

\subsubsection{Sediment chronology}

The sediment chronology was established using the following four different methods. (i) The ${ }^{137} \mathrm{Cs}$ method: we used the fallout radionuclide ${ }^{137} \mathrm{Cs}$ to derive quantitative information on sedimentation rates for the period from 1954 until present (Longmore, 1982). (ii) Total-P enrichment: the enrichment in total $\mathrm{P}$ of colluvial deposits relative to stable, non-aggrading locations; this was used to quantify rates of deposition since ca. 1910, when P fertiliser was first applied in Flanders (Hofman and Verloo, 1989). (iii) OSL dating: optically stimulated luminescence (OSL) dating utilises dosimetric properties of quartz and feldspar in sediments to determine the time of burial (e.g. Lang, 1994). Lastly, (iv) AMS radiocarbon dating: charcoals were selected from the cores for ${ }^{14} \mathrm{C}$ dating as a supplement to OSL dating. ${ }^{137} \mathrm{Cs}$ activity and total $\mathrm{P}$ were measured on samples from all three study sites; OSL dating was carried out at site B; and for site C, OSL and AMS radiocarbon ages from Rommens et al. (2007) were used.

i. The majority of ${ }^{137} \mathrm{Cs}$ was introduced to the environment by atmospheric nuclear weapons testing in the 1950s and 1960s. ${ }^{137} \mathrm{Cs}$ activity was measured using a hyperpure lithium-drifted germanium detector coupled to a Nuclear Data 6700 multichannel gamma-ray spectrophotometer at the University of Exeter and an HPGe detector (model no. GC2021) in a low-level configuration at K.U. Leuven. The maximum depth of ${ }^{137} \mathrm{Cs}$ occurrence at depositional locations was calculated as the average of the depths of the deepest sample with significant ${ }^{137} \mathrm{Cs}$ activity and the depth of the first sample showing ${ }^{137} \mathrm{Cs}$ activity of zero. Half the difference of these two depth values was taken as the range of error $(5-10 \mathrm{~cm})$.

ii. P fertiliser has been applied onto agricultural fields in the region since the beginning of the 20th century (Hofman and Verloo, 1989). The P concentration in the soil can therefore be used to identify sediments of 
Table 2. Sample code and depth; moisture content (\% by mass); U, Th and K content; $\alpha$-efficiency factor ( $a$ value); effective dose rate $(D / \mathrm{d} t)$; equivalent dose (De); and OSL ages for samples taken at the depositional location of site $\mathrm{B}^{\mathrm{a}}$.

\begin{tabular}{lrrrrrrrrr}
\hline Sample & $\begin{array}{r}\text { Depth } \\
{[\mathrm{cm}]}\end{array}$ & $\begin{array}{r}\text { Moisture } \\
{[\%]}\end{array}$ & $\begin{array}{r}\mathrm{U} \\
{[\mathrm{ppm}]}\end{array}$ & $\begin{array}{r}\mathrm{Th} \\
{[\mathrm{ppm}]}\end{array}$ & $\begin{array}{r}\mathrm{K} \\
{[\%]}\end{array}$ & $\begin{array}{r}a \text { value } \\
{\left[\mathrm{Gy} \mathrm{kyr}^{-1}\right]}\end{array}$ & $\begin{array}{r}\text { De } \\
{[\mathrm{Gy}]}\end{array}$ & $\begin{array}{r}\text { OSL age } \\
{[\mathrm{kyr}]}\end{array}$ \\
\hline LV481 & 315.5 & $15 \pm 5^{\mathrm{b}}$ & $4.00 \pm 0.10$ & $12.81 \pm 0.24$ & $1.63 \pm 0.04$ & 0.04 & $3.78 \pm 0.21$ & $11.30 \pm 0.47$ & $2.99 \pm 0.21$ \\
LV482 & 265.5 & $15 \pm 5$ & $3.20 \pm 0.08$ & $10.45 \pm 0.22$ & $1.77 \pm 0.04$ & 0.04 & $3.49 \pm 0.20$ & $8.20 \pm 0.29$ & $2.35 \pm 0.16$ \\
LV483 & 211 & $15 \pm 5$ & $3.32 \pm 0.09$ & $10.59 \pm 0.23$ & $1.98 \pm 0.05$ & 0.04 & $3.73 \pm 0.23$ & $7.69 \pm 0.28$ & $2.06 \pm 0.15$ \\
LV484 & 137.5 & $15 \pm 5$ & $3.74 \pm 0.09$ & $12.65 \pm 0.25$ & $1.80 \pm 0.04$ & 0.04 & $3.86 \pm 0.23$ & $3.23 \pm 0.18$ & $0.84 \pm 0.07$ \\
LV485 & 77.5 & $15 \pm 5$ & $3.10 \pm 0.08$ & $10.76 \pm 0.24$ & $1.98 \pm 0.05$ & 0.04 & $3.69 \pm 0.22$ & $3.25 \pm 0.12$ & $0.88 \pm 0.06$ \\
LV486 & 37.5 & $15 \pm 5$ & $3.27 \pm 0.08$ & $10.12 \pm 0.21$ & $1.68 \pm 0.04$ & 0.04 & $3.42 \pm 0.18$ & $1.58 \pm 0.09$ & $0.46 \pm 0.04$ \\
\hline
\end{tabular}

${ }^{a}$ Details for site $\mathrm{C}$ can be found in Rommens et al. (2007). ${ }^{\mathrm{b}}$ Numbers to the left of the plus-minus sign indicate the average, while numbers to the right of the plus-minus sign indicate standard deviation.

the past $100 \mathrm{yr}$ (Steegen, 2001; Rommens et al., 2007). The method relies on the enrichment of $\mathrm{P}$ below the plough layer at depositional locations, relative to background $\mathrm{P}$ concentrations at reference locations where no significant erosion or deposition has occurred. The depth difference between the deepest layer enriched in $\mathrm{P}$ at a depositional location and that of the plough layer at the reference location gives the depth of deposition since approximately 1910 . In a similar manner to ${ }^{137} \mathrm{Cs}$, we took the average depth of the two neighbouring points where significant decrease occurs and took half of the difference of the two depths as the range of errors $(2-6 \mathrm{~cm})$. Clearly, if manure was applied at this field before 1910 at an intensity that exceeded the agronomic demands, the phosphorus enrichment identified could pre-date 1910. However, given the limited $\mathrm{P}$ sources available to farmers before the arrival of fertilisers, this is unlikely. Total P content of each sample was determined using the method of Walker and Adams (described by Olsen and Sommers, 1982, and modified by Takken and Verstraten, 1996). This method uses $\mathrm{H}_{2} \mathrm{SO}_{4}$ to extract phosphorus from ignited soil samples.

iii. OSL dating has frequently been used to determine chronologies of hillslope deposits (e.g. Lang, 1994; Fuchs and Lang, 2009). Here we utilised a singlealiquot, regenerative-dose protocol (Murray and Wintle, 2000) on fine-grained quartz $(4-15 \mu \mathrm{m})$. Detailed procedures for sample preparation and measurement are given in Mauz et al. (2002). OSL ages may represent overestimates due to insufficient light exposure of quarts grains before deposition (Lang, 1994). Ages that did not fall in stratigraphic order were therefore excluded from chronology construction. OSL dates for site $\mathrm{C}$ were taken from Rommens et al. (2007), and additional data were collected for site B (Table 2). iv. ${ }^{14} \mathrm{C}$ dating of charcoal fragments incorporated in colluvium provides a maximum age of colluvium deposition. ${ }^{14} \mathrm{C}$ data provide information about the age of $\mathrm{C}$ fixation: this may be a close approximation of depositional age if charcoal production immediately precedes deposition, but can represent a large overestimation if charcoal was reworked many times before arriving at the sampling location (Lang and Hönscheidt, 1999; Edwards and Whittington, 2001). We used two ${ }^{14} \mathrm{C}$ dating results obtained by Rommens et al. (2007) for site $\mathrm{C}$. The radiocarbon age was calibrated using Oxcal v.3.10 (2005) (Bronk Ramsey, 2001), with the calibration curve based on atmospheric data from Reimer et al. (2004).

\subsubsection{C burial efficiency}

Colluvial soils are sites of deposition where, as a result of burial of former topsoil material, deep soils enriched in C develop (Quine and Van Oost, 2007). Colluvial soils therefore may be interpreted as chronostratigraphy in which young deposits are found at shallow depth and sediment age increases with depth (Van Oost et al., 2012). The efficiency of C burial can then be regarded as the fraction of deposited $\mathrm{C}$ that is preserved in the buried sediments. We estimated this fraction as the ratio between the SOC content of deposited sediments at the surface of depositional profiles and the SOC content of buried sediments for a range of sediment ages:

$\mathrm{CBE}_{z}=\frac{C_{z}}{C_{\mathrm{t}}}$,

where $\mathrm{CBE}_{z}$ denotes the $\mathrm{C}$ burial efficiency of sediments of a given age $z, C_{z}$ denotes the $\mathrm{C}$ content of sediments with a given age $z$, and $C_{\mathrm{t}}$ denotes the $\mathrm{C}$ content of the topsoil at the depositional locations. In the study area, deposition of soil eroded by water occurs mainly in the form of aggregates (Beuselinck et al., 2000). Therefore the $\mathrm{C}$ selectivity by erosion is limited and the $\mathrm{C}$ content of deposited sediments is similar to that of the topsoil in upslope areas (Wang et al., 2010). Additionally, deposited sediments are mixed into the 
Table 3. Scenarios used in C burial efficiency estimation.

\begin{tabular}{lll}
\hline Scenarios & Sediment age & Temporal SOC variation \\
\hline Low & $\begin{array}{l}\text { Youngest possible sediment age (i.e. highest } \\
\text { possible sedimentation rate) }\end{array}$ & $\begin{array}{l}\text { Current C content of the plough layer } 25 \% \\
\text { lower than before the onset of agricultural } \\
\text { mechanisation }\end{array}$ \\
\hline Medium & Most likely sediment age & $\begin{array}{l}\text { Current C content of the plough layer } 10 \% \\
\text { lower than before the onset of agricultural } \\
\text { mechanisation }\end{array}$ \\
\hline High & $\begin{array}{l}\text { Oldest possible sediment age (i.e. lowest possi- } \\
\text { ble sedimentation rate) }\end{array}$ & Plough layer C content constant through time \\
\hline
\end{tabular}

topsoil layer by tillage operation prior to burial below the cultivation layer by continued accretion. It can therefore be reasonably assumed that the $\mathrm{C}$ content of the sediment at the moment of burial below the topsoil equals that of the topsoil at depositional locations.

The estimation of $\mathrm{C}$ burial efficiency is associated with uncertainties that originate from (i) the quantification of sediment age and (ii) the estimation of the SOC content of the deposited sediment. Uncertainties associated with sediment ages for the four methods were derived from the depth sampling interval and analytical uncertainty of each age estimate, and we used the maximum range of the calculated ages, i.e. the oldest and youngest possible ages to illustrate this. The SOC content of eroding soils (and hence also that of the deposited sediment) is expected to vary temporally: for example, previous studies have found that the $\mathrm{C}$ storage in the cropland of Flanders or Belgium has experienced a decrease of $5-18 \%$ in the past decades (Lettens et al., 2005; Sleutel et al., 2003; Goidts and van Wesemael, 2007). Although it is not possible to reconstruct temporal changes in SOC content of surface soils for the last millennia, we assumed that a variation of $25 \%$ with respect to the current values is a realistic range. Therefore, we considered three scenarios, as listed in Table 3, to assess the uncertainties associated with our calculation of the $\mathrm{C}$ burial efficiency.

\section{Results}

\subsection{Sedimentation chronology}

The maximum depths at which ${ }^{137} \mathrm{Cs}$ occurs at depositional locations were $60.9 \pm 6.3 \mathrm{~cm}, 55.5 \pm 9.0 \mathrm{~cm}$ and $42.0 \pm 4.5 \mathrm{~cm}$ for sites A, B and C, respectively (Fig. 1). Assuming that the tracer was homogeneously mixed in a plough layer of $25 \mathrm{~cm}$, this allows calculating total sediment accumulation rates. Since 1954, sediment has accumulated over $35.9 \mathrm{~cm} \pm 6.3 \mathrm{~cm}, 30.5 \pm 9.0 \mathrm{~cm}$ and $17.0 \pm 4.5 \mathrm{~cm}$ at sites $\mathrm{A}, \mathrm{B}$ and $\mathrm{C}$, respectively. This results in an average deposition rate for the last five decades of $6.2 \pm 1.1 \mathrm{~mm} \mathrm{yr}^{-1}$, $5.3 \pm 1.6 \mathrm{~mm} \mathrm{yr}^{-1}$ and $2.9 \pm 0.8 \mathrm{~mm} \mathrm{yr}^{-1}$ at sites $\mathrm{A}, \mathrm{B}$ and $\mathrm{C}$, respectively.

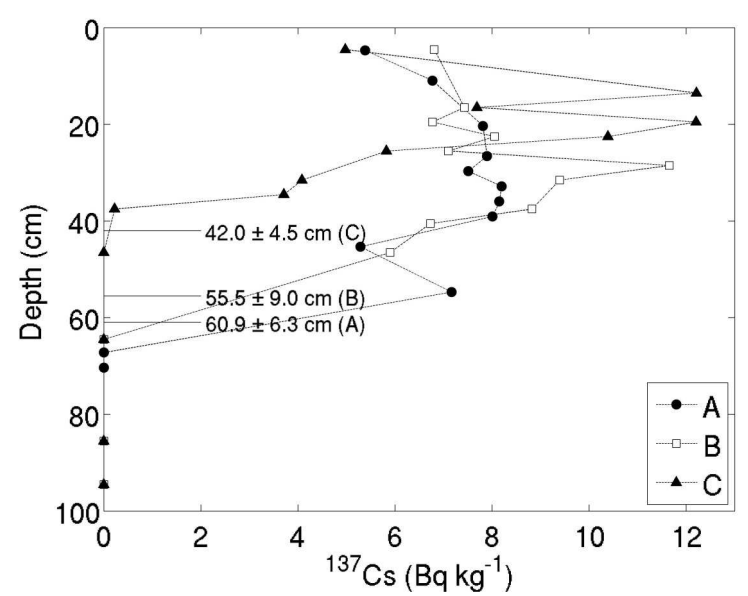

Fig. 1. ${ }^{137}$ Cs activities at the depositional locations at sites A, B and C. The numbers indicate the estimated maximum depth of ${ }^{137} \mathrm{Cs}$ occurrence and half the difference of the depths of the deepest sample with significant ${ }^{137} \mathrm{Cs}$ activity, and the depth of the sample following below showing ${ }^{137} \mathrm{Cs}$ activity of zero. The results of site A were obtained from the profile "colluvium 1" (see other figures).

The thickness of the P-enriched deposit was determined as $51.8 \pm 6.1 \mathrm{~cm}, 25.0 \pm 2.6 \mathrm{~cm}$, and $35.0 \pm 3.1 \mathrm{~cm}$ at sites $\mathrm{A}, \mathrm{B}$ and $\mathrm{C}$, respectively (Fig. 2), resulting in an average deposition rate over the last century of $5.2 \pm 0.6 \mathrm{~mm} \mathrm{yr}^{-1}$, $2.5 \pm 0.3 \mathrm{~mm} \mathrm{yr}^{-1}$ and $3.5 \pm 0.3 \mathrm{~mm} \mathrm{yr}^{-1}$ for sites A, B and $\mathrm{C}$, respectively. We do not place too much confidence in these values as identifying the level at which $\mathrm{P}$ decreased significantly was not always straightforward.

Our OSL and ${ }^{14} \mathrm{C}$ data indicate that over the last three millennia, deposition rates of site $\mathrm{B}$ ranged between 0.6 and $2.6 \mathrm{~mm} \mathrm{yr}^{-1}$, while for site $\mathrm{C}$, the deposition rates were between 0.7 and $1.6 \mathrm{~mm} \mathrm{yr}^{-1}$ (Fig. 3, Table 4). We combined all available data to construct a "most likely" sedimentation history for each of the study sites (Fig. 4). 

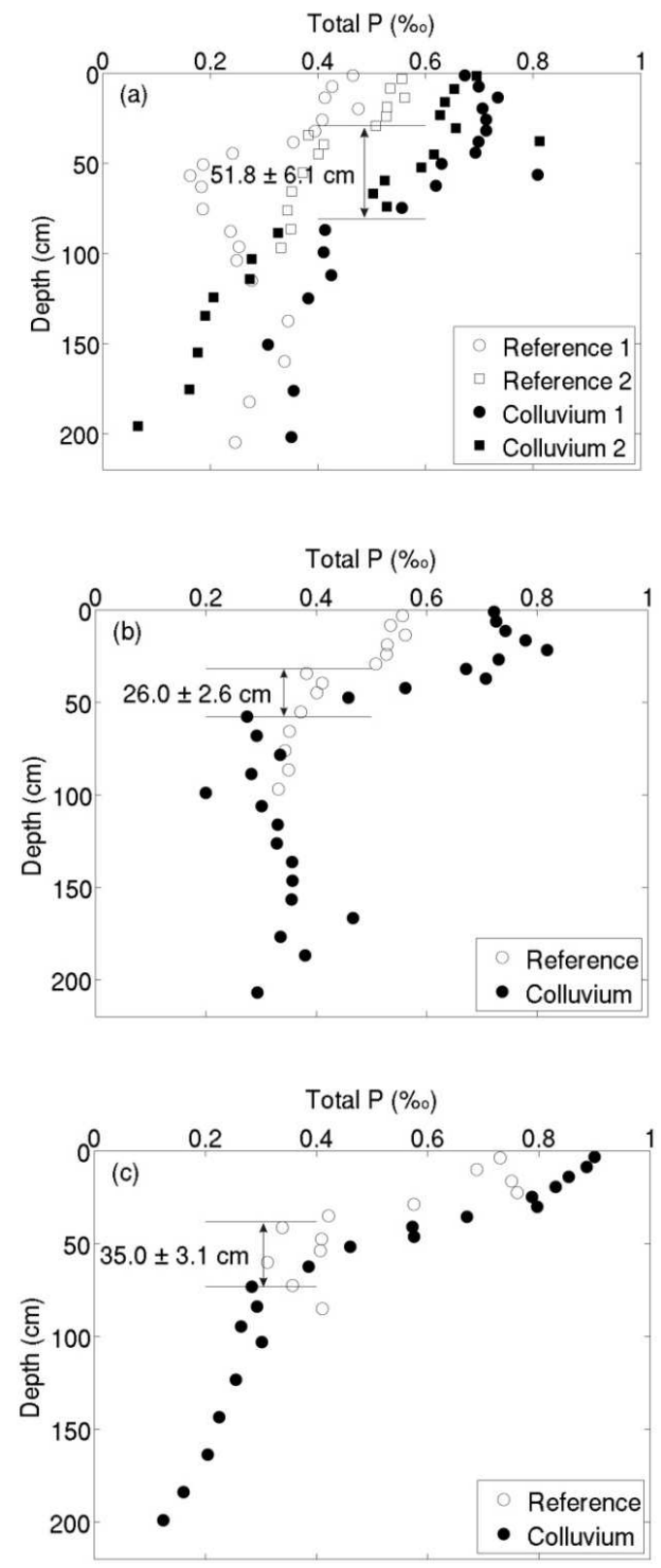

Fig. 2. $\mathrm{P}$ concentrations at depositional locations (filled symbols) and reference locations (open symbols) for sites A (a), B (b) and $\mathrm{C}$ (c). The double arrow indicates the depth difference between the original ploughing layer at depositional locations and at reference locations. The notations and numbers in panel a correspond to the profile "colluvium 1".

\subsection{SOC quantity and quality}

The depositional locations and the reference locations contained equivalent concentrations of SOC within the plough layer $(0-25 \mathrm{~cm})$, i.e. approximately $1 \%$, and no significant differences were found (Fig. 5, Table 5). In contrast, the SOC concentrations in the subsoil were significantly higher in the

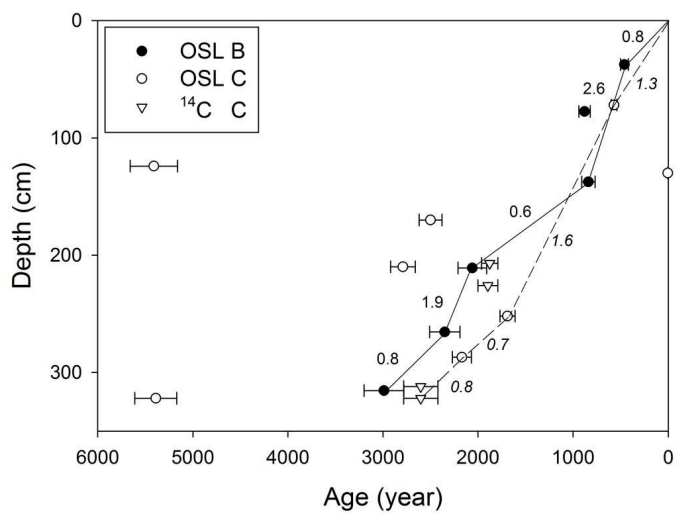

Fig. 3. OSL ages and calibrated radiocarbon ages versus sampling depth for the depositional locations at sites $\mathrm{B}$ and $\mathrm{C}$. The numbers indicate the most likely deposition rates $\left(\mathrm{mm} \mathrm{yr}^{-1}\right)$ of the corresponding stages. Results of site $\mathrm{C}$ were taken from Rommens et al. (2007).

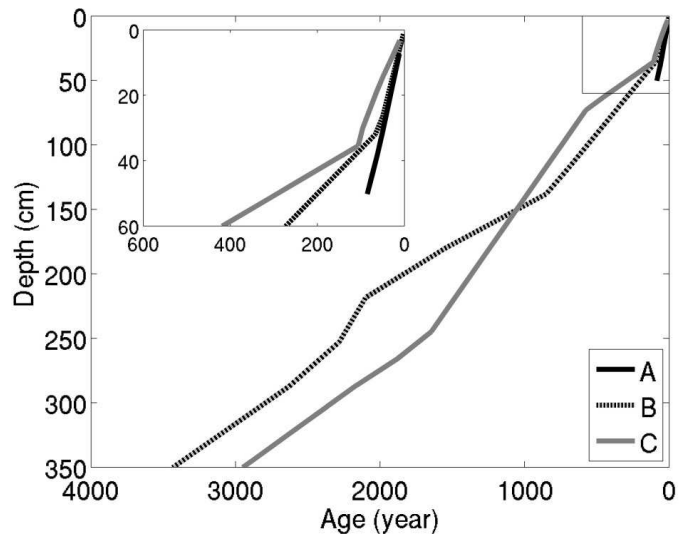

Fig. 4. Most likely sedimentation chronologies at depositional locations of sites A, B and C derived from ${ }^{137} \mathrm{Cs}$, total P, OSL and radiocarbon dating. Due to the lack of OSL or ${ }^{14} \mathrm{C}$ data of site $\mathrm{A}$, only results of the last $100 \mathrm{yr}$ are displayed for this site.

depositional profiles relative to the reference profiles, down to a depth of $1.25,1.75$ and $1 \mathrm{~m}$ for sites $\mathrm{A}, \mathrm{B}$ and $\mathrm{C}$, respectively. The SOC stocks between 25 and $100 \mathrm{~cm}$ at the depositional locations were 2.20, 1.85 and 1.73 times higher than that at the reference locations for sites A, B and C, respectively (Table 5).

The results of the soil incubation experiments showed that in the plough layer $(0-20 \mathrm{~cm})$, there were no significant differences in the soil respiration rate per unit $\mathrm{C}$ between the depositional and reference locations ( $p=0.176$, MannWhitney $U$ test; Fig. 6). In the subsoil $(20-200 \mathrm{~cm})$ the respiration rate per unit of $\mathrm{C}$ for the subsoil was significantly lower at the deposition locations compared to that of the reference locations ( $p<0.001$, Mann-Whitney $U$ test). 
Table 4. Deposition rates derived from OSL and radiocarbon dating for different time periods for sites $\mathrm{B}$ and $\mathrm{C}^{\mathrm{a}}$.

\begin{tabular}{lll}
\hline Site & Phase & $\begin{array}{l}\text { Deposition rate } \\
\left(\mathrm{mm} \mathrm{yr}^{-1}\right)\end{array}$ \\
\hline & 980 BC-340 BC & $0.78 \pm 0.09$ \\
& 340 BC-50 BC & $1.87 \pm 1.36$ \\
B & 50 BC-AD 1170 & $0.60 \pm 0.16$ \\
& AD 1170-AD 1550 & $2.63 \pm 1.18$ \\
& AD 1550-present & $0.82 \pm 0.10$ \\
\hline \multirow{3}{*}{ 600 BC-160 BC } & $0.80 \pm 0.39$ \\
C & 160 BC-AD 320 & $0.73 \pm 0.30$ \\
& AD 320-AD 1440 & $1.61 \pm 0.17$ \\
& AD 1440-present & $1.27 \pm 0.09$ \\
\hline
\end{tabular}

a Age information for site $\mathrm{C}$ is taken from Rommens et al. (2007).

Similar to the incubation results, the $\delta^{13} \mathrm{C}$ values in the plough layer $(0-25 \mathrm{~cm})$ did not show significant difference between the depositional locations and the reference location ( $p=0.10, t$ test; Fig. 7), while in the subsoil $(25-200 \mathrm{~cm})$ the $\delta^{13} \mathrm{C}$ values at the depositional locations were significantly higher than those at the reference location $(p=0.00043$, $t$ test).

\section{Discussion}

The observation that the sediment deposition rates for the past $50 \mathrm{yr}$, as derived from the ${ }^{137} \mathrm{Cs}$ tracer, were up to 2 times higher than those derived from the $\mathrm{P}$ profiles, which integrate the last $100 \mathrm{yr}$ is consistent with other studies. This recent increase in deposition rates can be attributed to the mechanisation of agriculture since the 1950s, which was previously shown to significantly enhance rates of tillage erosion and deposition (Van Oost et al., 2005b). Water erosion rates and especially the transfer of water-eroded soil to colluvial sites may also have increased due to changes in landscape structure (Van Oost et al., 2000).

The lack of significant differences in the $\mathrm{C}$ content between the depositional locations and the reference locations in the top soil layer (Fig. 5), is consistent with the observed similarity in $\mathrm{C}$ stability and $\mathrm{C}$ quality that we observed at the depositional and reference location at site A (Figs. 6 and 7). This is not unexpected: although topsoils are exposed to erosional perturbation, the $\mathrm{C}$ of the top soil is mainly controlled by the input from plant residues and roots and cycles very fast (Trumbore, 2000). Also, the deposited sediments in the surface layer are exposed to the same environmental conditions (i.e. temperature, climate, management, plant inputs, soil aggregation, etc.) as the reference locations and the mineralogical characteristics of the soils are also very similar (Doetterl et al., 2012a). As a result, the $\mathrm{C}$ content and C quality of the top soil do not show spatial variations within a
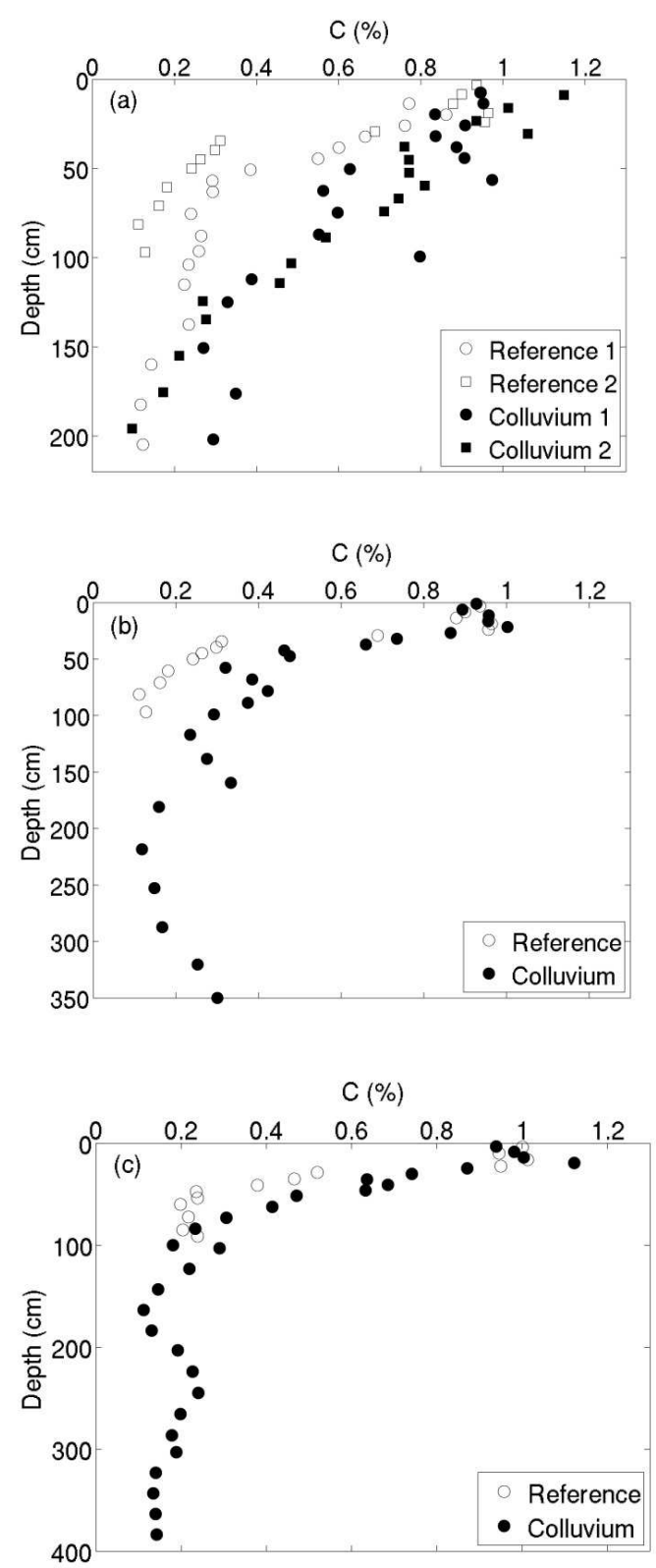

Fig. 5. C concentration at depositional locations (filled symbols) and reference locations (open symbols) at sites A (a), B (b) and C (c).

field and are only weakly associated with topographical variables, even if significant lateral fluxes of $\mathrm{C}$ due to erosion occur (De Gryze et al., 2007). Similar original C content and quality, soil conditions and $\mathrm{C}$ cycling processes therefore explain the observed similar $\mathrm{C}$ content and quality in the plough layer between the depositional and reference locations.

With continuous addition of newly deposited sediments, a fraction of the plough layer at colluvial sites becomes buried under the plough layer, where it is no longer mixed by tillage operations. As the C content of the plough layer is substantially higher than that of the subsoil under stable conditions, 
Table 5. Differences in $\mathrm{C}$ inventories and $\mathrm{C}$ contents between the depositional and reference locations for top- $(0-25 \mathrm{~cm})$ and subsoils $(25-100 \mathrm{~cm})$.

\begin{tabular}{|c|c|c|c|c|c|c|c|}
\hline \multirow[t]{2}{*}{ Site } & \multirow[t]{2}{*}{ Depth $(\mathrm{cm})$} & \multicolumn{2}{|c|}{$\mathrm{C}$ inventory $\left(\mathrm{Mg} \mathrm{Cha}^{-1}\right)$} & \multicolumn{2}{|c|}{$\mathrm{C}$ content $(\%)$} & \multirow[t]{2}{*}{ Test $^{\mathrm{a}}$} & \multirow[t]{2}{*}{$p$} \\
\hline & & Reference & Depositional & Reference & Depositional & & \\
\hline \multirow{2}{*}{ A } & $0-25$ & $30.38 \pm 2.19^{b}$ & $32.74 \pm 3.38$ & $0.90 \pm 0.065$ & $0.97 \pm 0.10$ & $t$ test & 0.15 \\
\hline & $25-100$ & $35.44 \pm 20.25$ & $77.96 \pm 15.19$ & $0.35 \pm 0.20$ & $0.77 \pm 0.15$ & Mann-Whitney $U$ test & $<0.001$ \\
\hline \multirow{2}{*}{ B } & $0-25$ & $31.39 \pm 1.25$ & $32.06 \pm 1.35$ & $0.93 \pm 0.037$ & $0.95 \pm 0.040$ & $t$ test & 0.44 \\
\hline & $25-100$ & $27.34 \pm 17.21$ & $50.63 \pm 19.24$ & $0.27 \pm 0.17$ & $0.50 \pm 0.19$ & Mann-Whitney $U$ test & 0.005 \\
\hline \multirow{2}{*}{$\mathrm{C}$} & $0-25$ & $33.08 \pm 1.15$ & $33.08 \pm 3.14$ & $0.98 \pm 0.034$ & $0.98 \pm 0.093$ & $t$ test & 0.90 \\
\hline & $25-100$ & $30.38 \pm 12.15$ & $52.65 \pm 19.24$ & $0.30 \pm 0.12$ & $0.52 \pm 0.19$ & $t$ test & 0.012 \\
\hline
\end{tabular}

a Statistical test refers to $\mathrm{C}$ contents. Mann-Whitney $U$ test was used if numbers were not normally distributed. ${ }^{\mathrm{b}}$ Numbers to the left of the plus-minus sign indicate the average, while numbers to the right of the plus-minus sign indicate standard deviation.

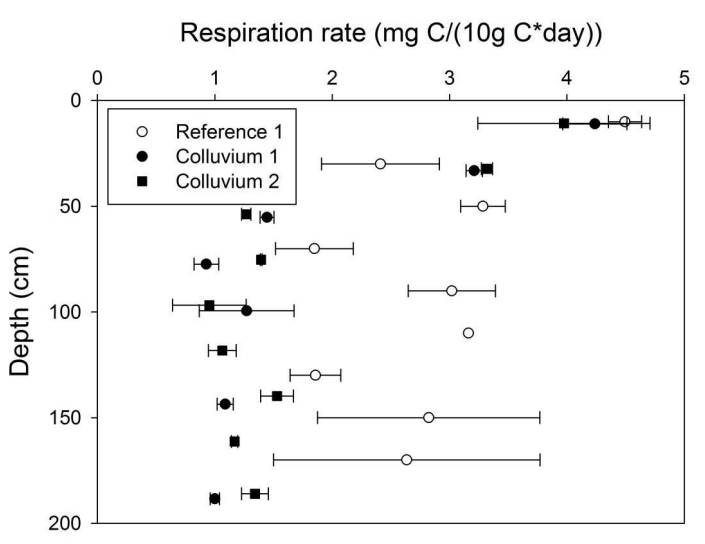

Fig. 6. Carbon respiration rates of profiles at depositional locations (filled symbols) and reference locations (open symbols) at site A averaged over the whole incubation period. The error bar indicates the standard error of the measurements.

the buried sediments under the plough layer are enriched in $\mathrm{C}$ as compared to the subsoil at the same depth at the reference locations (Fig. 5). For a reference location experiencing no erosion or deposition, the $\mathrm{C}$ content at a given depth is the result of the dynamic balance between in situ $\mathrm{C}$ input and decomposition. As these sites have been cultivated for several centuries, the $\mathrm{C}$ profiles at the reference locations can be regarded as being close to equilibrium with the environmental conditions. Our results clearly show that the buried sediments contain significantly more $\mathrm{C}$ than the equilibrium amount (i.e. the $\mathrm{C}$ at the same depth of the reference locations). If it is accepted that the environmental conditions controlling $\mathrm{C}$ inputs and decomposition are similar for the reference and depositional locations, the latter will lose $\mathrm{C}$ through post-depositional mineralisation. Therefore depositional locations will be a local source with respect to the atmospheric $\mathrm{CO}_{2}$. On the other hand, the fact that enrichment in SOC can be observed over significant depths in the subsoil indicates that the mineralisation of deposited SOC takes place over relatively long time spans.

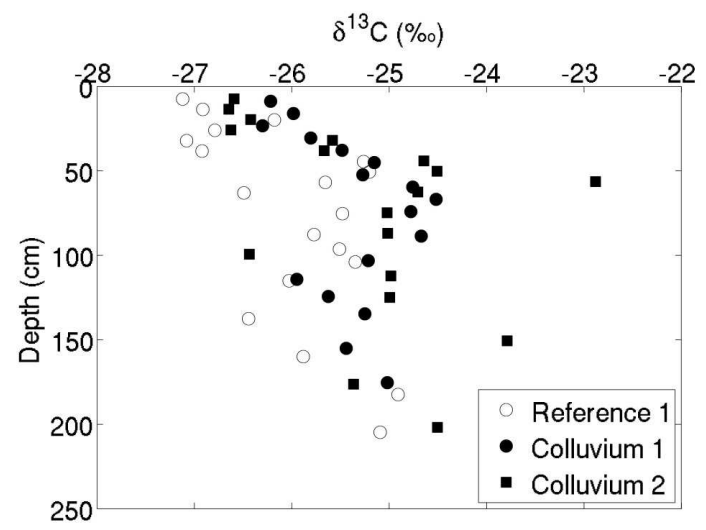

Fig. 7. Profiles of $\delta^{13} \mathrm{C}$ at depositional (filled symbols) and reference locations (open symbols) at site A.

The fresh $\mathrm{C}$ input from plants and roots can be assumed to be similar at the depositional and reference locations as variations in crop productivity in the area do not show a strong association with topographical attributes, which is essentially due to the homogeneity of the loess-derived soils in terms of soil physical characteristics (Reyniers et al., 2006). However, the mineralisation of the surplus SOC in the subsoil is expected to increase the fraction of recalcitrant SOC due to the fact that the labile fraction of deposited SOC is preferentially mineralised. Both the results of incubation experiments (Fig. 6) and of stable isotope analysis (Fig. 7) confirm that this is indeed the case and that the bulk SOC below the plough layer at the depositional locations is more recalcitrant and exhibits a higher degree of decomposition. This is in line with the finding by Berhe et al. (2008), who found that the SOC decomposition rate of buried OC was smaller than that of $\mathrm{C}$ in eroding or stable profiles at similar depths. However, both SOC recalcitrance and $\delta^{13} \mathrm{C}$ do not vary monotonically with depth and/or burial age. Rather, they appear to evolve relatively rapidly to a new equilibrium value. We hypothesise that this is due to the fact that different SOC fractions 
react differently after burial. Light, labile fractions are decomposed rapidly, after which a set of recalcitrant, heavy fractions remain: as soon as the labile, light fraction has been mineralised, the overall quality and recalcitrance of the SOC do not change significantly anymore with further decomposition.

Clearly, factors other than difference in C history may also be invoked to explain the observed variations in SOC quality. In particular, the stable isotope composition of SOC is known to be affected by a multitude of factors such as crop type (C3 vs. C4) and the type of plant tissue that is the source of the SOC. Nevertheless, such variations are unlikely to be of major importance in our study, because the comparison made is within individual fields, and therefore the crop rotation at the stable and depositional locations is the same.

As discussed above, the buried sediments do not retain the amount of $\mathrm{C}$ originally deposited, as their $\mathrm{C}$ content is higher than the equilibrium value (as derived from that of reference locations at the same depth). A plot of sediment age versus sediment $\mathrm{C}$ burial efficiency shows that the burial efficiency does not decrease linearly with time but instead shows a clear decrease until reaching a constant rate of approximately $17 \%$ (Fig. 8). This can be attributed to two mechanisms: (i) the $\mathrm{SOC}$ in the buried sediment becomes more degraded and recalcitrant with increasing burial time, resulting in a lower $\mathrm{C}$ decomposition, and (ii) with time the sediments are buried deeper in the soil profile, where the environmental factors controlling $\mathrm{C}$ decomposition (e.g. temperature, humidity and aeration) are likely to be less favourable. Although the results of the incubation experiments and isotopic characterisation provide direct evidence for mechanism 1, our estimates of burial efficiency reflect both mechanisms and we are unable to quantify their relative contribution.

Our study shows that the majority of the deposited SOC is mineralised on the timescale of centuries rather than decades. For example, it takes ca. $250-300 \mathrm{yr}$ to mineralise $50 \%$ of the buried $\mathrm{C}$ and an important fraction (approximately $17 \%$ ) of the deposited SOC is preserved over millennia. Nevertheless, it should be recognised that these values are most certainly not universal: the equilibrium $\mathrm{C}$ burial efficiency will depend on the type of crops grown, the climate and the soil type. Even within a specific agro-ecological setting the equilibrium $\mathrm{C}$ burial efficiency may be expected to vary with burial rate: when the sedimentation rate is high, the sediment will be buried more rapidly, thereby spending less time in the upper subsoils, where the environment is likely to be more favourable for SOC mineralisation. Rapid deposition may therefore result in a higher equilibrium $\mathrm{C}$ burial efficiency.

\section{Conclusions}

The quantification of the fate of SOC stored in colluvial soils in an agricultural environment that is subject to rapid erosion and deposition provides significant insights with respect to

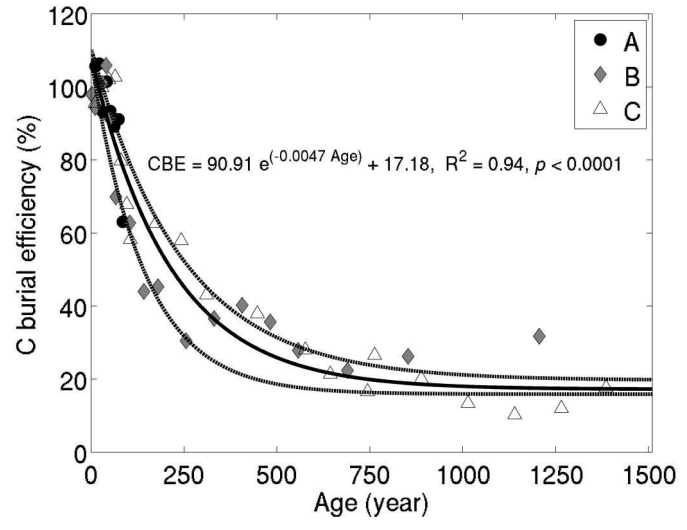

Fig. 8. Variation of $\mathrm{C}$ burial efficiency (CBE) with time for the three sites. The points denote the medium scenario. The solid line (middle) is fitted to the medium scenario, while the dotted lines display the effects of uncertainty on both original $\mathrm{C}$ content and deposition rate as calculated from a low (lower line) and high (upper line) scenarios (see Table 3 for details). Due to the lack of OSL or ${ }^{14} \mathrm{C}$ data of site A, only results of the last $100 \mathrm{yr}$ are shown for site A.

the role of depositional environments in the global $\mathrm{C}$ cycle. Our results show that, for the colluvial settings we studied, the assumption that buried $\mathrm{C}$ remains stable, while valid at the decadal scale considered in previous studies (Van Oost et al., 2007), is not tenable when longer timescales are considered. In the colluvial stores that we investigated, SOC decomposition takes place over a timescale of centuries, with $50 \%$ of the buried SOC decomposed after ca. $250-300 \mathrm{yr}$. However, a significant fraction of the buried SOC (ca. $17 \%$ for our sites) may be preserved over much longer timescales.

The rate at which deposited SOC is mineralised is initially rapid but decreases with time after burial. This implies that the role of soil erosion in global carbon cycling at the landscape scale may be temporally varying, with equilibrium being reached on the timescale of centuries. We attribute this decrease to two causes: increasing recalcitrance of the buried SOC with time and the less favourable environment for SOC decomposition with increasing depth.

While this study is one of the first to quantitatively constrain the fate of buried SOC, we should keep in mind that burial efficiency can be expected to depend on the type of crops grown, the climate, the soil type and the burial rate (with larger burial rates resulting in higher equilibrium $\mathrm{C}$ burial efficiency). Numerical modelling is necessary in order to quantify the SOC cycling processes and the relevant factors controlling these processes within colluvial soils.

Acknowledgements. We are grateful to M. Ayyad, L. Fondu, and S. Vandevelde for their help in field work and laboratory analysis.

Edited by: X. Wang 


\section{References}

Berhe, A. A., Harte, J., Harden, J. W., and Torn, M. S.: The significance of the erosion-induced terrestrial carbon sink, Bioscience, 57, 337-346, 2007.

Beuselinck, L., Steegen, A., Govers, G., Nachtergaele, J., Takken, I., and Poesen, J.: Characteristics of sediment deposits formed by intense rainfall events in small catchments in the Belgian Loam Belt, Geomorphology, 32, 69-82, 2000.

Bronk Ramsey, C.: Development of the radiocarbon calibration program., Radiocarbon, 43, 355-363, 2001.

Butterly, C., Marschner, P., McNeill, A., and Baldock, J.: Rewetting $\mathrm{CO}_{2}$ pulses in Australian agricultural soils and the influence of soil properties, Biol. Fertility of Soils, 46, 739-753, doi:10.1007/s00374-010-0481-9, 2010.

De Gryze, S., Bossuyt, H., Six, J., Van Meirvenne, M., Govers, G., and Merckx, R.: Factors controlling aggregation in a minimum and a conventionally tilled undulating field, Euro. J. Soil Sci., 58, 1017-1026, doi:10.1111/j.1365-2389.2006.00881.x, 2007.

Doetterl, S., Six, J., Van Wesemael, B., and Van Oost, K.: Carbon cycling in eroding landscapes: geomorphic controls on soil organic C pool composition and C stabilization, Glob. Change Biol., 18, 2218-2232, doi:10.1111/j.1365-2486.2012.02680.x, 2012a.

Doetterl, S., Van Oost, K., and Six, J.: Towards constraining the magnitude of global agricultural sediment and soil organic carbon fluxes, Earth Surf. Process. Landf., 37, 642-655, doi:10.1002/esp.3198, 2012b.

Edwards, K. J. and Whittington, G.: Lake sediments, erosion and landscape change during the Holocene in Britain and Ireland, Catena, 42, 143-173, doi:10.1016/S0341-8162(00)001363, 2001.

Fuchs, M. and Lang, A.: Luminescence dating of hillslope deposits-A review, Geomorphology, 109, 17-26, doi:10.1016/j.geomorph.2008.08.025, 2009.

Galy, V., France-Lanord, C., Beyssac, O., Faure, P., Kudrass, H., and Palhol, F.: Efficient organic carbon burial in the Bengal fan sustained by the Himalayan erosional system, Nature, 450, 407410, 2007.

Goidts, E. and van Wesemael, B.: Regional assessment of soil organic carbon changes under agriculture in Southern Belgium (1955-2005), Geoderma, 141, 341-354, 2007.

Govers, G.: Rill erosion on arable land in Central Belgium: Rates, controls and predictability, Catena, 18, 133-155, 1991.

Govers, G., Vandaele, K., Desmet, P., Poesen, J., and Bunte, K.: The role of tillage in soil redistribution on hillslopes, Euro. J. Soil Sci., 45, 469-478, 1994.

Harris, D., Horwath, W. R., and van Kessel, C.: Acid fumigation of soils to remove carbonates prior to total organic carbon or carbon-13 isotopic analysis, Soil Sci. Soc. Am. J., 65, 18531856, 2001.

Hofman, G. and Verloo, M.: Minerale Meststoffen., in: Milieuzorg in de landbouw, edited by: De Coster, M., Pelckmans, 141-173, 1989.

Lal, R.: Soil erosion and the global carbon budget, Environment Int., 29, 437-450, 2003.

Lang, A.: Infra-red stimulated luminescence dating of holocene reworked silty sediments, Quaternary Sci. Rev., 13, 525-528, doi:10.1016/0277-3791(94)90071-X, 1994.
Lang, A. and Hönscheidt, S.: Age and source of colluvial sediments at Vaihingen-Enz, Germany, Catena, 38, 89-107, doi:10.1016/S0341-8162(99)00068-5, 1999.

Lettens, S., van Orshoven, J., van Wesemael, B., Muys, B., and Perrin, D.: Soil organic carbon changes in landscape units of Belgium between 1960 and 2000 with reference to 1990, Global Change Biol, 11, 2128-2140, 2005.

Li, Y., Zhang, Q. W., Reicosky, D. C., Lindstrom, M. J., Bai, L. Y., and Li, L.: Changes in soil organic carbon induced by tillage and water erosion on a steep cultivated hillslope in the Chinese Loess Plateau from 1898-1954 and 1954-1998, J. Geophys. Res. Biogeosciences, 112, G01021, doi:10.1029/2005jg000107, 2007.

Longmore, M. E.: The caesium-137 dating technique and associated applications in Australia- A review, in: Archaeometry. An Australasian Perspective, edited by: Ambrose, W., and Duerden, P., Australian National University Press, Canberra, 310-321, 1982.

Mauz, B., Bode, T., Mainz, E., Blanchard, H., Hilger, W., Dikau, R., and Zöller, L.: The luminescence dating laboratory at the University of Bonn: equipment and procedures, Ancient TL, 20, 53-61, 2002.

Mayorga, E., Aufdenkampe, A. K., Masiello, C. A., Krusche, A. V., Hedges, J. I., Quay, P. D., Richey, J. E., and Brown, T. A.: Young organic matter as a source of carbon dioxide outgassing from Amazonian rivers, Nature, 436, 538-541, 2005.

Murray, A. S. and Wintle, A. G.: Luminescence dating of quartz using an improved single-aliquot regenerative-dose protocol, Radiation Measurements, 32, 57-73, doi:10.1016/S13504487(99)00253-X, 2000.

Natelhoffer, K. J. and Fry, B.: Controls On Natural Nitrogen15 And Carbon-13 Abundances In Forest Soil Organic Matter, Soil Sci. Soc. Am. J., 52, 1633-1640, doi:10.2136/sssaj1988.03615995005200060024x, 1988.

Notebaert, B., Verstraeten, G., Vandenberghe, D., Marinova, E., Poesen, J., and Govers, G.: Changing hillslope and fluvial Holocene sediment dynamics in a Belgian loess catchment, J. Quaternary Sci., 26, 44-58, doi:10.1002/jqs.1425, 2011.

Olsen, S. R. and Sommers, L. E.: Phosphorus, in: Methods of soil analysis. Part 2. Chemical and microbiological properties, 2nd Edn., edited by: Page, A. L. and Miller, R. H., ASA and SSSA, Madison, WI, 403-430, 1982.

Quine, T. A. and Van Oost, K.: Quantifying carbon sequestration as a result of soil erosion and deposition: retrospective assessment using caesium-137 and carbon inventories, Glob. Change Biol., 13, 2610-2625, 2007.

Raymond, P. A. and Bauer, J. E.: Riverine export of aged terrestrial organic matter to the North Atlantic Ocean, Nature, 409, 497500, 2001.

Reimer, P. J., Baillie, M. G. L., Bard, E., Bayliss, A., Beck, J. W., Bertrand, C. J. H., Blackwell, P. G., Buck, C. E., Burr, G. S., Cutler, K. B., Damon, P. E., Edwards, R. L., Fairbanks, R. G., Friedrich, M., Guilderson, T. P., Hogg, A. G., Hughen, K. A., Kromer, B., McCormac, G., Manning, S., Ramsey, C. B., Reimer, R. W., Remmele, S., Southon, J. R., Stuiver, M., Talamo, S., Taylor, F. W., van der Plicht, J., and Weyhenmeyer, C. E.: IntCal04 terrestrial radiocarbon age calibration, 0-26 cal kyr BP, Radiocarbon, 46, 1029-1058, 2004.

Reyniers, M., Maertens, K., Vrindts, E., and De Baerdemaeker, J.: Yield variability related to landscape properties of a loamy soil in central Belgium, Soil Till. Res., 88, 262-273, 2006. 
Ritchie, J. C., McCarty, G. W., Venteris, E. R., and Kaspar, T. C.: Soil and soil organic carbon redistribution on the landscape, Geomorphology, 89, 163-171, 2007.

Rommens, T., Verstraeten, G., Poesen, J., Govers, G., Van Rompaey, A., Peeters, I., and Lang, A.: Soil erosion and sediment deposition in the Belgian loess belt during the Holocene: establishing a sediment budget for a small agricultural catchment, Holocene, 15, 1032-1043, 2005.

Rommens, T., Verstraeten, G., Peeters, I., Poesen, J., Govers, G., Van Rompaey, A., Mauz, B., Packman, S., and Lang, A.: Reconstruction of late-Holocene slope and dry valley sediment dynamics in a Belgian loess environment, Holocene, 17, 777-788, 2007.

Rosen, P. and Hammarlund, D.: Effects of climate, fire and vegetation development on Holocene changes in total organic carbon concentration in three boreal forest lakes in northern Sweden, Biogeosciences, 4, 975-984, doi:10.5194/bg-4-975-2007, 2007.

Sleutel, S., De Neve, S., Hofman, G., Boeckx, P., Beheydt, D., Van Cleemput, O., Mestdagh, I., Lootens, P., Carlier, L., Van Camp, N., Verbeeck, H., Vande Walle, I., Samson, R., Lust, N., and Lemeur, R.: Carbon stock changes and carbon sequestration potential of Flemish cropland soils, Global Change Biol., 9, 11931203, 2003.

Smith, S. V. Sleezer, R. O., Renwick, W. H., and Buddemeier, R. W.: Fates of eroded soil organic carbon: Mississippi basin case study, Ecol. Appl., 15, 1929-1940, doi:10.1890/05-0073, 2005.

Steegen, A.: Sediment deposition in and export from small agricultural catchments, PhD, K.U. Leuven, Leuven, 2001.

Takken, I. and Verstraten, J. M.: Een verkennend onderzoek naar bepalingsmethoden voor plant-beschikbaar fosfor en organisch fosfor in bodemmonsters uit de Nederlandse kustduinen., in: De rol van fosfor bij de vergrassing in de droge delen van de Nederlandse kustduinen, FGBL-UvA-intern rapport., 1996.

Thomsen, I. K., Kruse, T., Bruun, S., Kristiansen, S. M., Knicker, H., Petersen, S. O., Jensen, L. S., Holst, M. K., and Christensen, B. T.: Characteristics of soil carbon buried for 3300 years in a Bronze Age burial mound, Soil Sci. Soc. Am. J., 72, 1292-1298, 2008.

Trimble, S. W.: Decreased Rates of Alluvial Sediment Storage in the Coon Creek Basin, Wisconsin, 1975-93, Science, 285, 1244 1246, doi:10.1126/science.285.5431.1244, 1999.

Trumbore, S.: Age of soil organic matter and soil respiration: Radiocarbon constraints on belowground $\mathrm{C}$ dynamics, Ecological Applications, 10, 399-411, 2000.

Vancampenhout, K., Wouters, K., Caus, A., Buurman, P., Swennen, R., and Deckers, J.: Fingerprinting of soil organic matter as a proxy for assessing climate and vegetation changes in last interglacial palaeosols (Veldwezelt, Belgium), Quaternary Res., 69, 145-162, 2008.
VandenBygaart, A. J., Kroetsch, D., Gregorich, E. G., and Lobb, D.: Soil C erosion and burial in cropland, Global Change Biol., 18, 1441-1452, doi:10.1111/j.1365-2486.2011.02604.x, 2012.

Van Oost, K., Govers, G., and Desmet, P.: Evaluating the effects of changes in landscape structure on soil erosion by water and tillage, Landscape Ecol., 15, 577-589, 2000.

Van Oost, K., Govers, G., Quine, T. A., Heckrath, G., Olesen, J. E., De Gryze, S., and Merckx, R.: Landscape-scale modeling of carbon cycling under the impact of soil redistribution: The role of tillage erosion, Global Biogeochem. Cy., 19, GB4014, doi:10.1029/2005gb002471, 2005a.

Van Oost, K., Van Muysen, W., Govers, G., Deckers, J., and Quine, T. A.: From water to tillage erosion dominated landform evolution, Geomorphology, 72, 193-203, 2005b.

Van Oost, K., Quine, T. A., Govers, G., De Gryze, S., Six, J., Harden, J. W., Ritchie, J. C., McCarty, G. W., Heckrath, G., Kosmas, C., Giraldez, J. V., da Silva, J. R. M., and Merckx, R.: The impact of agricultural soil erosion on the global carbon cycle, Science, 318, 626-629, 2007.

Van Oost, K., Verstraeten, G., Doetterl, S., Notebaert, B., Wiaux, F., Broothaerts, N., and Six, J.: Legacy of human-induced C erosion and burial on soil-atmosphere $\mathrm{C}$ exchange, Proceedings of the National Academy of Sciences, 109, 19492-19497, doi:10.1073/pnas.1211162109, 2012.

Vanwalleghem, T., Verheyen, K., Hermy, M., Poesen, J., and Deckers, J.: Legacies of Roman land-use in the present-day vegetation in Meerdaal forest (Belgium)?, Belgian J.Botany, 137, 181-187, doi:10.2307/20794552, 2004.

Vanwalleghem, T., Poesen, J., Van Den Eeckhaut, M., Nachtergaelel, J., and Deckers, J.: Reconstructing rainfall and land-use conditions leading to the development of old gullies, Holocene, 15, 378-386, doi:10.1191/0959683605hl807rp, 2005.

Verstraeten, G., Poesen, J., Demaree, G., and Salles, C.: Long-term (105 years) variability in rain erosivity as derived from 10-min rainfall depth data for Ukkel (Brussels, Belgium): Implications for assessing soil erosion rates, J. Geophys. Res. Atmos., 111, D22109, doi:10.1029/2006jd007169, 2006.

Wang, Z., Govers, G., Steegen, A., Clymans, W., Van den Putte, A., Langhans, C., Merckx, R., and Van Oost, K.: Catchment-scale carbon redistribution and delivery by water erosion in an intensively cultivated area, Geomorphology, 124, 65-74, 2010.

Wang, Z., Govers, G., Van Oost, K., Clymans, W., Van den Putte, A., and Merckx, R.: Soil organic carbon mobilization by interrill erosion: Insights from size fractions, J. Geophys. Res. Earth Surf., 118, 348-360, doi:10.1029/2012jf002430, 2013.

Zhang, J. H., Quine, T. A., Ni, S. J., and Ge, F. L.: Stocks and dynamics of SOC in relation to soil redistribution by water and tillage erosion, Global Change Biol., 12, 1834-1841, 2006. 